\title{
BM] Global Health Incorporating future unrelated medical costs in cost-effectiveness analysis in China
}

\author{
Shan Jiang (D) , ${ }^{1}$ Yitong Wang, ${ }^{2}$ Junwen Zhou, ${ }^{3}$ Yawen Jiang (D) , ${ }^{4}$ Gordon G Liu, ${ }^{5}$ \\ Jing $\mathrm{Wu}^{6}$
}

To cite: Jiang S, Wang $Y$, Zhou J, et al. Incorporating future unrelated medical costs in cost-effectiveness analysis in China. BMJ Global Health 2021;6:e006655. doi:10.1136/ bmjgh-2021-006655

\section{Handling editor Lei $\mathrm{Si}$}

- Additional supplemental material is published online only. To view, please visit the journal online (http://dx.doi.org/10. 1136/bmjgh-2021-006655).

Received 17 June 2021 Accepted 30 September 2021

Check for updates

(C) Author(s) (or their employer(s)) 2021. Re-use permitted under CC BY-NC. No commercial re-use. See rights and permissions. Published by BMJ.

${ }^{1}$ School of Population and Public Health, The University of British Columbia, Vancouver, British Columbia, Canada

${ }^{2}$ Public Health Department, AixMarseille-University, Marseille, France

${ }^{3}$ Health Economics Research Centre, Nuffield Department of Population Health, University of Oxford, Oxford, UK

${ }^{4}$ School of Public Health (Shenzhen), Sun Yat-Sen University, Guangzhou, China ${ }^{5}$ National School of

Development, Peking University, Beijing, China

${ }^{6}$ School of Pharmaceutical Science and Technology, Tianjin University, Tianjin, China

Correspondence to

Professor Jing Wu;

jingwu@tju.edu.cn

\section{ABSTRACT}

The occurrence of future unrelated medical costs is a direct consequence of life-prolonging interventions, but most pharmacoeconomic guidelines recommend the exclusion of these costs. The Chinese guidelines were updated in 2020, taking an exclusion approach for the future unrelated medical cost. We notice the research surrounding this issue continues in other countries and leads to an inclusion recommendation in some guidelines. Meanwhile, this issue has not been discussed in China reflecting an urgent need for extensive research on its impact. We reviewed the theoretical and practical studies surrounding the inclusion of future unrelated medical costs, summarised the landscape of guidelines in other jurisdictions. We found that the inclusion would increase the internal and external consistency of economic evaluation and the comparability of results between different jurisdictions. However, more research is needed surrounding this issue. We proposed a future research agenda to inform the update of Chinese guidelines. We recommend research on individual-level healthcare reimbursement data and end-of-life costs from hospital administrative data to generate the age-specific, sexspecific and condition-specific costs. We also recommend establishing a formal process to evaluate the ethical and economic impact of including future unrelated medical costs and adjust the threshold accordingly in the guidelines.

\section{BACKGROUND}

Through cost-effectiveness analysis (CEA), healthcare researchers incorporate health benefits (eg, life-years gained) and costs to evaluate and compare different healthcare programmes and thereby make recommendations to decision-makers on the allocation of health resources. ${ }^{1}$ The National Institute for Health and Care Excellence (NICE) in the UK published national pharmacoeconomic guidelines to the CEA practice, and so did some other countries (eg, Canada, Australia). China published the first version of pharmacoeconomic guidelines in 2011 and updated it in 2020 to guide the CEAs in China. ${ }^{2}$ In
Summary box

What is already known?

- Including future unrelated medical costs in costeffectiveness analysis is in debate and some health technology assessment (HTA) guidelines recommend an inclusion approach.

What are the new findings?

- We reviewed the studies supporting the exclusion or inclusion approach and the HTA guidelines in 43 jurisdictions about their recommendations towards future unrelated medical costs. The inclusion of future unrelated medical costs in cost-effectiveness analysis would increase the internal and external consistency and the comparability of analysis results between different jurisdictions.

What do the new findings imply?

- We proposed a research agenda that what types of fundamental research would inform the Chinese guidelines on estimating future unrelated medical costs.

the updated version, a societal perspective is recommended, especially when the expenditure is publicly funded. The guidelines make it clear that, under the societal perspective, all direct, indirect and intangible costs should be included. Direct costs refer to costs related to the intervention under economic evaluation, whereas indirect costs refer to productivity loss in the guidelines. Intangible costs refer to the physical and psychological discomfort (eg, pain, anxiety, tension) caused by the intervention of interest, being captured by the quality-adjusted life-years (QALYs). The guidelines do not recommend a unified incremental cost-effectiveness ratio (ICER) threshold for economic evaluation. Instead, a range is recommended that lies between one and three times the per capita gross domestic product. Researchers may select a threshold within the range according to the context where the evaluation is conducted. 
Although CEA is increasingly used to assess whether healthcare interventions produce value for money, many methodological challenges exist in China that require attention. ${ }^{34}$ One such issue is whether to include future medical costs in CEA and, if so, to what extent they should be included. ${ }^{5}$ Future medical costs are incurred by future medical consumption during the life-years gained that would not have been consumed without a life-extending intervention. They are typically divided into future 'related' and 'unrelated' medical costs. The former refers to costs associated with treatments in the extended life that are directly related to the disease being treated by the life-extending intervention. For example, a heart transplant surgery extends a patient's life, who should thereafter routinely visit a cardiologist to ensure the heart works normally. The costs associated with the visits are future related medical costs. The latter-future unrelated medical costs-refers to all the costs associated with diseases in the extended life that are not related to the disease and the life-extending intervention of interest. Therefore, future unrelated medical costs are the consequences of the life-extending intervention from a societal perspective. In the above-mentioned example, if the patient experiences cancer during the extended life, the costs associated with the cancer treatment belong to future unrelated medical costs.

Future-related medical costs are typically included in current CEA practice. Nevertheless, it is still in a debate whether to include future unrelated medical costs in CEA ${ }^{67}$ This issue has not been discussed among Chinese health economists, because the latest guidelines do not include future unrelated medical costs in the cost inventory. $^{2}$ In contrast, this line of research continues in other countries and leads to the recommendation of including such costs. ${ }^{8}$ Since the Chinese guidelines prioritise the societal perspective, the issue of future unrelated medical costs deserves an extensive discussion. Therefore, we reviewed the theoretical debate surrounding the inclusion of future unrelated medical costs and the recommendations by official pharmacoeconomic guidelines in other jurisdictions and proposed an agenda for future research on this issue in China.

We conducted a scoping review of studies discussing the inclusion of future unrelated medical costs in CEA. The search was conducted in EMBASE and MEDLINE. We used two categories of keywords: (1) terms regarding future unrelated medical cost, including 'future cost', 'future medical cost', 'unrelated cost', 'unrelated medical cost' and 'survivor cost' and (2) terms regarding economic evaluation, including 'cost-effectiveness analysis', 'cost-utility analysis', 'cost-benefit analysis', 'health technology assessment' and 'economic evaluation'. We conducted the search in May 2021. The inclusion criteria were: (1) peer-reviewed articles discussing the inclusion of future unrelated medical costs in CEA and (2) CEA studies if the analysis was an example to assess the impact of including future costs. In addition, to provide a landscape of official recommendations on the inclusion of

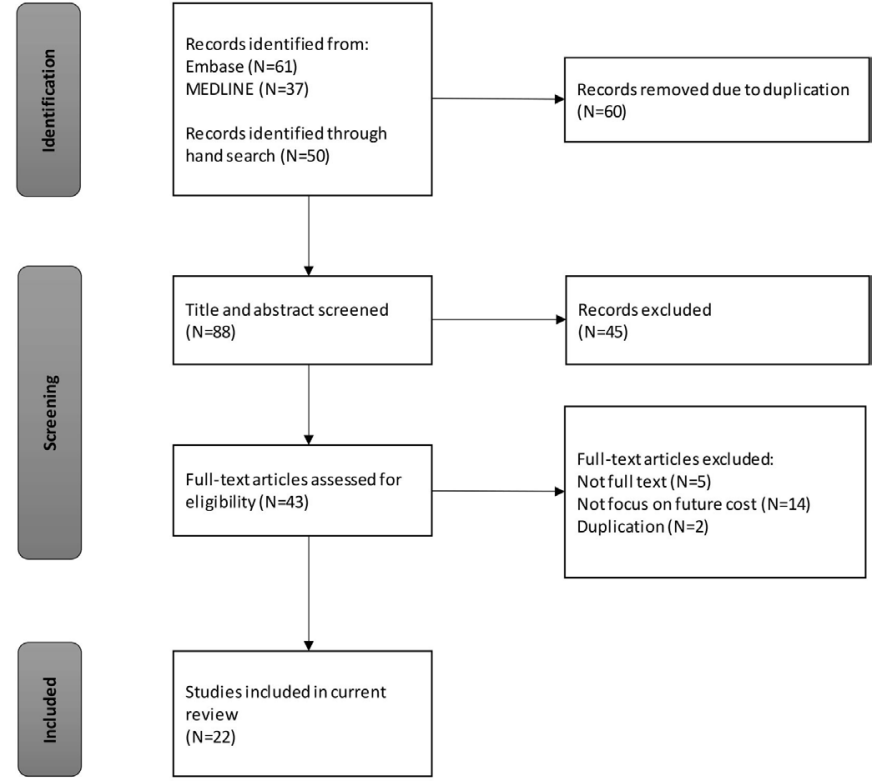

Figure 1 Flow chart for the search of eligible studies (attached as a separate PDF).

future unrelated medical costs, we referred to the Professional Society for Health Economics and Outcomes Research website to search for the pharmacoeconomic guidelines of different jurisdictions.

Two authors (SJ and YW) independently screened the search results to examine their eligibility for inclusion. The references of included studies were also examined to prevent the missing of relevant studies. For the included articles, we extracted their bibliographic and methodological information, opinions and conclusions. For official guidelines, we extracted the bibliographic information (ie, country, year, organisation, title) and their recommendations on whether to include future unrelated medical costs. Patients or the public were not involved in the design, or conduct, or reporting, or dissemination plans to research. We finally included 22 articles (figure 1). Their main conclusions are presented in table 1 and bibliographic information in online supplemental table S1. Through the review of these articles, we summarised their opinions and associated evidence as below.

\section{ARGUMENTS SUPPORTING EXCLUSION}

First, a widely spread argument is that the new treatments should be evaluated independently. ${ }^{1}$ It argues that when economic evaluation is being made, there is no commitment to deliver future unrelated care; as such, future unrelated medical care is not a necessary consequence of the life-prolonging intervention and should be excluded. The independence also implies that the future unrelated care could be evaluated separately, apart from the intervention of interest.

Second, some researchers admitted that the incurrence of future unrelated medical costs was a consequence of life-prolonging intervention, but the exclusion 
Table 1 An overview of studies discussing the inclusion of future unrelated medical costs in cost-effectiveness analysis

\begin{tabular}{|c|c|c|c|c|c|}
\hline Author & Area & Year & Article type & Recommendation & Key points on unrelated medical costs \\
\hline Meltzer ${ }^{18}$ & USA & 1997 & Economic model & Inclusion & $\begin{array}{l}\text { Cost-effectiveness criteria are strictly consistent with a model of lifetime } \\
\text { utility maximisation only if they account for effects on future related and } \\
\text { unrelated medical expenditures. } \\
\text {.The magnitude of unrelated medical expenditures, consumption, and } \\
\text { earnings may be large enough to alter the cost-effectiveness. }\end{array}$ \\
\hline $\begin{array}{l}\text { Garber and } \\
\text { Phelps }\end{array}$ & USA & 1997 & Economic model & Exclusion & $\begin{array}{l}\text { The inclusion or exclusion of future unrelated medical costs will not affect } \\
\text { the ranking of cost effectiveness ratios, so that they can be neglected. } \\
\text { The inclusion of future unrelated medical costs will only add a constant } \\
\text { figure to all cost-effectiveness ratios. }\end{array}$ \\
\hline $\begin{array}{l}\text { Meltzer and } \\
\text { Johannesson }^{41}\end{array}$ & USA & 1999 & Review & Inclusion & $\begin{array}{l}\text { The US Panel made inconsistent recommendations by not including the } \\
\text { future unrelated costs, which would seriously distort comparisons of } \\
\text { healthcare programmes. } \\
\text { The inconsistency could be corrected by including the future unrelated } \\
\text { costs, either medical or non-medical. }\end{array}$ \\
\hline van Baal et a $\left.\right|^{20}$ & NL & 2007 & $\begin{array}{l}\text { Economic model } \\
\text { and case study }\end{array}$ & Inclusion & $\begin{array}{l}\text { For primary prevention only a cost utility ratio that includes both the } \\
\text { costs and effects of unrelated medical care meets the criterion of internal } \\
\text { consistency and is related to a meaningful decision problem. }\end{array}$ \\
\hline Rappange et $a^{6}{ }^{6}$ & NL & 2008 & Review & Inclusion & $\begin{array}{l}\text { Only inclusion of all costs and effects of unrelated medical care in life-years } \\
\text { gained can be considered both internally and externally consistent. } \\
\text { Including or excluding unrelated future medical costs may have important } \\
\text { distributional consequences, especially for interventions that substantially } \\
\text { increase length of life. } \\
\text { It is becoming increasingly possible to accurately estimate unrelated } \\
\text { medical costs in life-years gained. }\end{array}$ \\
\hline $\begin{array}{l}\text { Garber and } \\
\text { Phelps }^{10}\end{array}$ & USA & 2008 & Editorial & Exclusion & $\begin{array}{l}\text { If the future costs were truly unrelated, it did not matter whether such costs } \\
\text { were included or excluded, as long as the cost effectiveness threshold was } \\
\text { properly adjusted. }\end{array}$ \\
\hline
\end{tabular}

\begin{tabular}{|c|c|c|c|c|c|}
\hline $\operatorname{Lee}^{11}$ & USA & 2008 & Economic model & Exclusion & $\begin{array}{l}\text { The controversy for unrelated future costs in the literature is due to } \\
\text { differences in modelling budget constraints. } \\
\text { Analyses that use a Conditional budget constraint imply that unrelated } \\
\text { future costs need not be considered. } \\
\text { Analyses that use an Annuity budget constraint imply that future savings by } \\
\text { a wide range of unrelated future costs need to be considered. } \\
\text { The paper goes on to argue that Conditional budget constraints are } \\
\text { preferable. } \\
\text { Health maximisation and utility maximisation require accounting for the } \\
\text { present value related future costs and ignoring unrelated future costs. } \\
\text { It is difficult to disentangle 'related' costs from 'unrelated' costs. }\end{array}$ \\
\hline Meltzer $^{12}$ & USA & 2008 & Correspondence & Inclusion & $\begin{array}{l}\text { Economic models of intertemporal resource allocation to maximise utility } \\
\text { under uncertainty imply that all future costs net of earnings should be } \\
\text { included in cost-effectiveness analysis. }\end{array}$ \\
\hline Feenstra et $a l^{42}$ & NL & 2008 & Correspondence & Inclusion & $\begin{array}{l}\text { Lee's paper did not resolve any controversy on the inclusion of future } \\
\text { unrelated medical costs. } \\
\text { The practical problems in estimating are not unique nor sufficient reasons to } \\
\text { ignore them and progress has been made for estimation. }\end{array}$ \\
\hline Grima et $a l^{16}$ & $\mathrm{CA}$ & 2013 & Correspondence & Exclusion & $\begin{array}{l}\text { Dialysis costs should be considered unrelated to a life-extending therapy. } \\
\text { Exclusion future unrelated costs is entirely consistent with current } \\
\text { pharmacoeconomic guidelines and clinical practice, providing cost- } \\
\text { effectiveness ratios that are comparable to other products. }\end{array}$ \\
\hline Gros et al ${ }^{44}$ & ES & 2015 & Review & Inclusion & $\begin{array}{l}\text { All relevant costs for the perspective selected should probably be included } \\
\text { in economic evaluations including related or unrelated, direct or indirect } \\
\text { future costs. }\end{array}$ \\
\hline Morton et $\left.a\right|^{31}$ & UK & 2016 & Editorial & Inclusion & $\begin{array}{l}\text { There is no rationale for excluding unrelated future costs, while at the same } \\
\text { time including unrelated future benefits in an economic evaluation. } \\
\text { Including the costs of future healthcare decisions may make a material } \\
\text { difference to results. } \\
\text { Including 'related' but excluding 'unrelated' future costs requires analysts to } \\
\text { make judgements about whether particular costs are related or unrelated. }\end{array}$ \\
\hline
\end{tabular}


Table 1 Continued

\begin{tabular}{llll}
\hline Author & Area & Year Article type & Recommendation Key points on unrelated medical costs
\end{tabular}

van Baal et $a l^{15}$ NL 2016 Economic model Inclusion and case study

- Practical relevance of including the costs of future unrelated medical care is illustrated using the example of transcatheter aortic valve implantation.

- The optimal decisions within a healthcare perspective require future unrelated medical costs to be included.

- Consistency requires that the benefits of unrelated medical care should also be excluded if costs thereof are excluded.

- Excluding the costs and benefits in some circumstances may erroneously result in labelling a cost-effective intervention as cost-ineffective.

\begin{tabular}{ccrll|} 
van Baal et al ${ }^{17}$ & NL & 2017 & $\begin{array}{l}\text { Head-to-head } \\
\text { debate }\end{array}$ & Mixed \\
van Lier et al & NL $2018 \begin{array}{l}\text { Review and } \\
\text { survey }\end{array}$ & Inclusion
\end{tabular}

- Inclusion: van Baal et al thought more health would result from including all future care costs in decisions to approve interventions.

- Exclusion: Sarah Davis worried that always including unrelated costs might lead to unfair distribution of care, including among people with incurable illness.

A consensus was not reached on the inclusion of healthcare costs unrelated to the intervention (round 1,53\% agreement; round 2, 50\% agreement).

- Panellists in favour of inclusion argued that unrelated future healthcare costs should theoretically be included if an intervention prolongs life and if important differences in future costs between interventions are expected.

- Others argued against inclusion on the basis that the calculations are difficult as many assumptions are made.

- The steering committee recommended the inclusion of related and unrelated future healthcare costs if the intervention is expected to result in an extension of life, because it represent a true use of resources.

$\mathrm{McCabe}^{45} \quad \mathrm{CA} 2019$ Commentary Exclusion

Tew et a/46 AU 2019 Empirical Inclusion

- Economic evaluation is rarely to identify and quantify the impact of ill health but informs decisions about whether a specific technology should be funded from fixed budget. Therefore, consideration of the scope of costs and benefits for inclusion has a normative component that derives from the policy objectives.

- The expansion of the scope of costs and benefits beyond direct costs and health accruing to the treated individuals may lead to unintended effects on the distribution.

- There is value in the inclusion of future medical costs in economic evaluation to support decision-makers' considerations relating to future healthcare budgets.

- This study demonstrated the practicability of including future medical costs in an economic evaluation in cancer patients.

- There is considerable heterogeneity in the ICERs across different cancer types and the types of future costs included do not impact all cancers consistently.

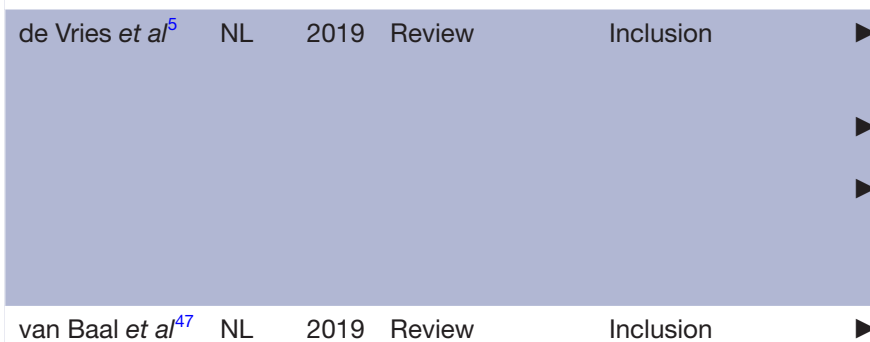

To allow optimal decisions, both from a healthcare and societal perspective including the additional related and unrelated medical costs in economic evaluations is required.

- Knowledge on how to estimate future (unrelated) medical costs has improved, also allowing inclusion in practice.

- Inclusion of these costs would presumably benefit most from lowering the practical difficulties and the burden on the analyst of including these costs in a cost-effectiveness analysis, as well as guidelines prescribing or at least encouraging inclusion rather than prescribing exclusion.

van Baal et al/7 NL 2019 Review Inclusion

- Including the costs of unrelated medical care makes sense as these costs also contribute to the health gains which are implicitly included in practice.

- Future unrelated costs are real and will affect the budget left for other care.

- Ignoring future unrelated medical costs results in an underestimate of QALY losses of unidentified patients in the future.

- For some patient groups, including future unrelated medical costs may imply a huge increase in the ICER for life-prolonging technologies and thereby trigger difficult ethical debates.

\begin{tabular}{|c|c|c|c|c|c|}
\hline $\begin{array}{l}\text { Kellerborg et } \\
\mathrm{al}^{14}\end{array}$ & NL & 2020 & Guideline & Inclusion & $\begin{array}{l}\text { The practical difficulties around the estimation of future costs can be } \\
\text { overcome. } \\
\text { The case studies demonstrate that including future costs, even just } \\
\text { unrelated medical costs, can have a substantial effect on the ICER, which } \\
\text { could affect decision-makers' choices. }\end{array}$ \\
\hline $\begin{array}{l}\text { Perry-Duxbury } \\
\text { et } a l^{19}\end{array}$ & $\mathrm{NL}$ & 2020 & Empirical study & Inclusion & $\begin{array}{l}\text { The results show that including future unrelated medical costs is feasible } \\
\text { and standardisable. } \\
\text { Empirical examples show that this inclusion leads to an increase in the ICER } \\
\text { of between } 7 \% \text { and } 13 \% \text {. }\end{array}$ \\
\hline
\end{tabular}

AU, Australia; CA, Canada; ES, Spain; ICER, incremental cost-effectiveness ratio; NL, the Netherlands; QALYs, quality-adjusted life-years. 
of these costs would not affect the ranking of the costeffectiveness ratios of alternative interventions. ${ }^{9-11}$ For example, Garber and Phelps argued that, based on their theoretical model, including the future costs would only add a constant figure to all the ratios and excluding these costs would simplify the calculation. ${ }^{9}$ Their conclusion was based on the assumption that patient's consumption plus medical expenditures were equal to earnings in each period. $^{12}$

Third, some researchers emphasised the difficulties in estimating the future unrelated medical costs as an argument not to include these costs. ${ }^{713}$ Indeed, taking a bottom-up approach and predicting the risk of unrelated diseases in the future seems very difficult, if not impossible. ${ }^{14}$ Another concern is the difficulties when disentangling the 'related' and 'unrelated' costs. ${ }^{15}$ In practice, it is impossible to identify a 'clear-cut' between the two categories because we rarely know the covariance between future diseases. The two difficulties may place an extreme analytic burden on researchers.

Fourth, the ethical concern is another reason supporting the exclusion. ${ }^{1617}$ Some researchers were concerned that the inclusion might cause the removal of some interventions previously funded by public insurance and the patients' lives would be threatened. ${ }^{17}$ A frequently mentioned example is dialysis. ${ }^{17}$ When assessing a lifeextending intervention in patients receiving dialysis, if the costs of dialysis as the future unrelated medical care are included, the value of life-years gained by the intervention may not outweigh the cost of dialysis. In that case, the intervention will not be funded even if it is provided at zero cost.

\section{ARGUMENTS SUPPORTING INCLUSION}

All arguments supporting exclusion have received rebuttals. In contrast to the first argument supporting the exclusion, some researchers argued that future unrelated medical care would usually be funded and cause real opportunity costs in the future. ${ }^{15}$ Because the healthcare authority functions intertemporally and future medical costs are part of opportunity cost considered by the authority. Therefore, it makes no sense to exclude future unrelated costs just because they are independent of the intervention being evaluated.

Second, unlike Garber and Phelps's model, Meltzer developed a generalised model, proving that lifetime utility maximisation would only be achieved by accounting for future related and unrelated medical costs. ${ }^{18}$ He appraised the models by Garber and Phelps and by Lee and criticised that the assumptions of their models were based on unrealistic assumptions that were difficult to justify. ${ }^{12}$ In his model, Meltzer relaxed the assumptions and assumed that future medical costs vary under different conditions. Meltzer demonstrated that the inclusion of future unrelated medical costs could be large enough to alter the rank of cost-effectiveness ratios of different interventions. Therefore, to ensure that the health resources are distributed unbiasedly, including future unrelated medical costs is necessary.

Third, the concerns regarding the practical difficulties have been refuted. ${ }^{19}$ Although the difficulties exist, the estimation of ageing effect on healthcare expenditure shed light on how we could predict the future unrelated medical costs. ${ }^{17}$ Instead of predicting future risk of unrelated diseases, we could apply a top-down approach and use the healthcare expenditure per capita by age and sex to estimate the average future medical costs. ${ }^{14}$ In the Netherlands, this approach has been applied by a group of health economists to develop a future cost estimation tool, known as Practical Application to Include Future Disease Costs (PAID) ${ }^{14}$ They linked the age-specific and sex-specific per-capita medical costs to the survival curves and then add these costs to the cost inventory of the intervention in research to approximate the total future medical costs. This approach has made the estimation feasible and straightforward. Moreover, the inclusion of future unrelated medical costs would reduce the analytic burden. In contrast to the exclusion approach, which requires researchers to disentangle 'related' and 'unrelated' costs, the inclusion approach makes it unnecessary to disentangle the two types but consider them all, which is a relief to CEA analysts.

Fourth, the ethical concerns have been refuted. ${ }^{517}$ Since the future unrelated medical costs are real opportunity costs, indicating that people in the future may use the money for health gains, the inclusion has ethical implications. If we ignore these costs, are we willing to sacrifice the health gains of patients in the future? As van Baal $e t$ $a l$ said, 'Pretending that future unrelated medical costs do not exist is equivalent to deeming the lives of some future patients worthless, which is neither fair nor ethically acceptable. ${ }^{17}$ The ignorance of these costs is always inappropriate in dealing with ethical questions, threatening the credibility of CEAs. If we care about the ethical issues, we should address them through a formal process to assess the ethical impact of the inclusion and evaluate whether the budget has been optimally allocated.

In addition to the rebuttals, researchers provided other arguments supporting the inclusion, one of which is about the internal consistency of CEA. ${ }^{52021}$ In the current practice, the improved quality of life and prolonged lifeyears are projected in the analysis. Implicitly, the health benefits require the use of unrelated medical care in the future. It is internally inconsistent to include the future benefits derived from unrelated medical care but exclude the associated costs. To ensure internal consistency, Nyman developed rules and required that all costs producing projected health benefits be included. ${ }^{22}$

Another argument is that excluding future unrelated medical costs would underestimate the opportunity cost of life-prolonging interventions. ${ }^{15}$ This argument is connected to the rebuttal to the ethical concerns. Under a fixed intertemporal healthcare budget, life-prolonging interventions will consume some budgets in the future. The consumption will lead to a decrease in the per-capita 
healthcare budget in the future. In this sense, the lifeprolonging interventions cause opportunity costs for others in the future. Thus, intervention with very high opportunity costs may simply mean it is unattractive and should not be invested.

External consistency is another argument. ${ }^{6}{ }^{20}$ Some researchers argued that the CEAs should be most informative for decision-makers. Thus, excluding future unrelated medical costs would decrease the external validity of CEA, as it reduces the amount of useful information for decision making.

\section{A LANDSCAPE OF CURRENT GUIDELINES IN OTHER JURISDICTIONS}

A total of 43 guidelines from 41 jurisdictions are summarised in table 2 with references presented in online supplemental table S2. Of the 43 guidelines, most (60\%) do not specify the inclusion or exclusion of future unrelated medical costs in CEA. Three guidelines $(7 \%)$ from the USA and the Netherlands recommend an inclusion approach. The second panel guidelines from the USA indicate that both the healthcare sector perspective and societal perspective need to include the future related and unrelated medical costs. The Institute for Clinical and Economic Review (ICER) guidelines from the US also recommend the inclusion approach and presenting a separate scenario analysis by excluding future unrelated medical costs when an intervention that increases QALYs is found to be cost-ineffective. The Netherlands guidelines indicate that if the intervention could increase the life expectancy, both related and unrelated future medicals costs should be considered. This is the first national guideline that make the inclusion approach mandatory. It is worth noting that the Swedish guidelines experienced a back-and-forth process on the inclusion of future unrelated medical costs. ${ }^{23}$ In 2013, the guidelines prescribed an inclusion approach. In 2015, the guidelines were changed by excluding future unrelated medical costs.

Contrarily, 11 guidelines (26\%) explicitly recommend an exclusion approach, while most of them do not provide justifications. The NICE guidelines currently exclude future unrelated medical costs from the analysis. ${ }^{24}$ However, it is reviewing the inclusion in its guidance. $^{25}$ Three guidelines (7\%) from Hungary, Belgium and Germany recommend excluding the future unrelated medical costs in the base case and considering them in the separate analysis if they were deemed essential for some interventions.

\section{A RESEARCH AGENDA TO INFORM CHINESE GUIDELINES}

By summarising the arguments supporting the exclusion and inclusion of future unrelated medical costs, we found a growing consensus that the inclusion has a solid theoretical basis. While practical difficulties exist, researchers have made progress in addressing these issues. However, we found that most pharmacoeconomic guidelines do not yet respond to the methodological progress on this issue, whereas only a few guidelines recognise the importance of this issue and recommend inclusion. Since Chinese pharmacoeconomic guidelines prescribe a societal perspective, this issue is worthy of more attention than other methodological and ethical challenges that persist in China. ${ }^{46}$ We acknowledge that recent CEAs have made efforts in defining a clear cost inventory for the Chinese population; ${ }^{27-29}$ however, we deem that more research is needed to reduce methodological difficulties concerning future unrelated medical costs.

First, due to the establishment of province-level electronic reimbursement systems in recent years, most Chinese provinces have accumulated individual-level reimbursement records. Though the variables are limited (eg, age, sex, health condition and reimbursed payment), these data may play as a starting point in estimating the future unrelated medical costs, as what has been done in PAID. ${ }^{21}$ For example, researchers may use the data to establish regression models to predict the age-specific, sex-specific and condition-specific costs paid by the reimbursement system. Since there is no provincial administrative data in most Chinese provinces, the numbers derived from the regression models may provide a justifiable estimate of future unrelated medical costs for patient lives. The regression results could also be used to calculate condition-specific total costs because the condition-specific reimbursement rate is transparent.

Second, the end-of-life costs are unclear in China. Since the healthcare expenditure is usually concentrated in the last stage of life, ${ }^{21}{ }^{30}$ it is essential to figure out how much has been spent at the end-of-life stage by diseaserelated groups (DRGs). A possible approach is to work with provincial top-tier hospitals and use the hospital administrative data to establish regression models for end-of-life cost estimation by DRGs. As a result, given that the intervention of interest belongs to one DRG, the end-of-life costs of other DRGs contribute largely to the future unrelated medical costs.

Third, the literature discussing future unrelated medical costs implicitly assumes that the standard of care for the unrelated future diseases and associated expenditure remains the same in the projected lifeyears gained..$^{31}$ This is an unrealistic assumption because healthcare technologies advance over time, and the standard of care and associated costs would change accordingly. However, it would be extremely difficult to predict how we may deal with health conditions in the future and how the technology progress may alter the costs. As a starting point, we may assume that healthcare technology develops constantly in the future and the associated costs decrease at a corresponding rate. With this assumption, we could establish functions to predict the future unrelated medical costs, based on the amount derived from the provincial reimbursement data.

Fourth, the Chinese Health Technology Assessment (HTA) agencies and health economists should establish a formal process to evaluate the ethical and economic 
Table 2 Recommendations on future unrelated medical costs by official guidelines for economic evaluation in different jurisdictions

\begin{tabular}{|c|c|c|c|c|}
\hline Country/area & Guidelines & Year & $\begin{array}{l}\text { Inclusion or } \\
\text { exclusion }\end{array}$ & Recommendations (if available) \\
\hline \multicolumn{5}{|l|}{ Africa } \\
\hline Egypt & $\begin{array}{l}\text { Recommendations for Reporting } \\
\text { Pharmacoeconomic Evaluations in Egypt }\end{array}$ & 2013 & Not specified & $\begin{array}{l}\text { Direct medical costs should be included. } \\
\text { Other direct non-medical and indirect costs paid by } \\
\text { patients, including lost productivity costs, might be } \\
\text { included only in the sensitivity analysis. }\end{array}$ \\
\hline \multicolumn{5}{|l|}{ Latin America } \\
\hline Brazil & $\begin{array}{l}\text { Methodological Guidelines: Economic } \\
\text { Evaluation of Health Technologies }\end{array}$ & 2014 & Not specified & $\begin{array}{l}\text { The included cost components should be described in } \\
\text { detail and separated by type of cost (medical-hospital } \\
\text { rights, non-medical-hospital, indirect and intangible } \\
\text { direct cost). }\end{array}$ \\
\hline Cuba & $\begin{array}{l}\text { Methodological Guidelines for Health } \\
\text { Economic Evaluation }\end{array}$ & 2003 & Not specified & $\begin{array}{l}\text { All relevant cost data should be clearly identified and } \\
\text { explained in detail. }\end{array}$ \\
\hline Mexico & $\begin{array}{l}\text { Economic Assessment Study Guideline } \\
\text { for Updating the National Formulary in } \\
\text { Mexico }\end{array}$ & 2015 & Not specified & $\begin{array}{l}\text { The suggested perspective only included the direct } \\
\text { costs. }\end{array}$ \\
\hline $\begin{array}{l}\text { MERCOSUR } \\
\text { (Argentina, } \\
\text { Brazil, } \\
\text { Paraguay, } \\
\text { Uruguay) }\end{array}$ & $\begin{array}{l}\text { Guideline for Economic Evaluation of } \\
\text { Health Technologies }\end{array}$ & 2015 & Not specified & $\begin{array}{l}\text { The costs such as direct healthcare costs, indirect } \\
\text { costs, patient and family costs and productivity loss } \\
\text { should be appropriate for the chosen perspective. }\end{array}$ \\
\hline
\end{tabular}

\section{North America}

\begin{tabular}{|c|c|c|c|c|}
\hline USA & $\begin{array}{l}\text { ICER's Base case for Economic } \\
\text { Evaluations: Principles and Rationale }\end{array}$ & 2020 & Inclusion & $\begin{array}{l}\text { In cases where an intervention that increases QALYs is } \\
\text { not found to be cost effective, even with a zero-dollar } \\
\text { price, a separate scenario analysis excluding unrelated } \\
\text { (non-drug) healthcare costs will be presented. }\end{array}$ \\
\hline Canada & $\begin{array}{l}\text { Guidelines for the Economic Evaluation } \\
\text { of Health Technologies: Canada fourth } \\
\text { Edition }\end{array}$ & 2017 & Not specified & $\begin{array}{l}\text { The evaluation should include all relevant resources } \\
\text { and costs based on the perspective of funded } \\
\text { healthcare payer. }\end{array}$ \\
\hline Japan & $\begin{array}{l}\text { Guideline for Preparing } \\
\text { Cost-Effectiveness Evaluation to the } \\
\text { Central Social Insurance } \\
\text { Medical Council }\end{array}$ & 2019 & Exclusion & $\begin{array}{l}\text { Healthcare costs of each health state include only } \\
\text { related costs that are directly affected by the selected } \\
\text { technology and do not include unrelated costs. }\end{array}$ \\
\hline Malaysia & $\begin{array}{l}\text { Pharmacoeconomic guidelines for } \\
\text { Malaysia second edition }\end{array}$ & 2019 & Not specified & $\begin{array}{l}\text { All direct costs relevant to the services borne by the } \\
\text { payer. }\end{array}$ \\
\hline $\begin{array}{l}\text { Taiwan of } \\
\text { China }\end{array}$ & $\begin{array}{l}\text { Guidelines of Methodological Standards } \\
\text { for Pharmacoeconomic Evaluations } \\
\text { (V.1.1, draft) }\end{array}$ & 2008 & Exclusion & $\begin{array}{l}\text { For the extended life-year cost, the costs those are not } \\
\text { related to target disease should be excluded. }\end{array}$ \\
\hline
\end{tabular}


Table 2 Continued

\begin{tabular}{|c|c|c|c|c|}
\hline Country/area & Guidelines & Year & $\begin{array}{l}\text { Inclusion or } \\
\text { exclusion }\end{array}$ & Recommendations (if available) \\
\hline South Korea & $\begin{array}{l}\text { Korean Guidelines for } \\
\text { Pharmacoeconomic Evaluation } \\
\text { (Second and Updated Version) }\end{array}$ & 2013 & Exclusion & $\begin{array}{l}\text { All costs not including productivity costs, unrelated } \\
\text { future medical cost should be considered. }\end{array}$ \\
\hline Israel & $\begin{array}{l}\text { Guidelines for the Submission of a } \\
\text { Request to Include a Pharmaceutical } \\
\text { Product in the National List of Health } \\
\text { Services }\end{array}$ & 2010 & Not specified & $\begin{array}{l}\text { The costs are direct and indirect medical costs. } \\
\text { If use of the new technology requires or spares } \\
\text { spending on other medical technologies, these costs } \\
\text { should be included in the calculation. }\end{array}$ \\
\hline Thailand & $\begin{array}{l}\text { Guidelines for health technology } \\
\text { assessment in Thailand (second edition) }\end{array}$ & 2014 & Not specified & $\begin{array}{l}\text { The choice whether to include or exclude future } \\
\text { unrelated costs will depend on the payer requirement } \\
\text { and perspective. }\end{array}$ \\
\hline
\end{tabular}

\begin{tabular}{llll}
\hline Europe & $\begin{array}{l}\text { Guidelines on Health Economic } \\
\text { Evaluation Consensus paper }\end{array}$ & 2006 & Not specified \\
\hline Denmark & $\begin{array}{l}\text { The Danish Approach to Standards for } \\
\text { Economic Evaluation Methodologies }\end{array}$ & 1997 & Not specified \\
Hungary & $\begin{array}{l}\text { Professional Healthcare Guideline on } \\
\text { the Methodology of Health Technology } \\
\text { Assessment }\end{array}$ & $\begin{array}{l}\text { Exclusion in } \\
\text { base case. } \\
\text { Inclusion in } \\
\text { supplementary } \\
\text { analysis }\end{array}$
\end{tabular}

Guidance to applicants for the
submission of pharmacoeconomic
analysis within the Pricing and
Reimbursement Dossier

2020 Not specified

Fundamentally, all costs relevant to the chosen perspective must be determined and included in the analysis.

All relevant costs should be considered including direct, indirect and intangible costs

- Indirect and intangible costs should be reported separately and valued on if they are considered relevant.

Costs generated due to diseases not related to the given health service, costs emerging in the life lengthened by the therapy but not due to the disease examined in the analysis, or other indirect costs cannot be presented, or, in justified cases, can be presented in additional analyses.

Russian Guidelines for Conducting a Comparative 2016 Not specified

Federation Clinical and Economic Evaluation of Drugs

In the base case, it is required to include the direct healthcare costs in line with the NHS perspective.

- Indirect costs and non-health care costs could be considered in a supplementary analysis from the societal perspective.

Direct medical costs are mandatory.

- Accounting for other types of costs remains at the discretion of researchers and different types of costs are indicated separately.

\begin{tabular}{|c|c|c|c|c|}
\hline Spain & $\begin{array}{l}\text { Spanish Recommendations on Economic } \\
\text { Evaluation of Health Technologies }\end{array}$ & 2010 & Not specified & $\begin{array}{l}\text { The societal perspective is recommended considering all } \\
\text { the related costs. }\end{array}$ \\
\hline Croatia & $\begin{array}{l}\text { The Croatian Guideline for Health } \\
\text { Technology Assessment Process and } \\
\text { Reporting }\end{array}$ & 2011 & Not specified & $\begin{array}{l}\text { Where measurable and relevant, indirect costs and } \\
\text { costs falling outside of Croatian Institute for Health } \\
\text { Insurance should be reported separately. }\end{array}$ \\
\hline $\begin{array}{l}\text { Baltic (Latvia, } \\
\text { Lithuania, } \\
\text { Estonia) }\end{array}$ & $\begin{array}{l}\text { Baltic Guideline for Economic Evaluation } \\
\text { of Pharmaceuticals (Pharmacoeconomic } \\
\text { Analysis) }\end{array}$ & 2002 & Not specified & $\begin{array}{l}\text { The suggested perspective includes only direct } \\
\text { healthcare costs. } \\
\text { If relevant, include all costs outside healthcare system, } \\
\text { presented separately. }\end{array}$ \\
\hline Belgium & $\begin{array}{l}\text { Belgian Guidelines for Economic } \\
\text { Evaluations and Budget Impact Analyses: } \\
\text { Second Edition }\end{array}$ & 2015 & $\begin{array}{l}\text { Exclusion in } \\
\text { base case; } \\
\text { Inclusion in } \\
\text { supplementary } \\
\text { analysis }\end{array}$ & $\begin{array}{l}\text { Costs borne outside the healthcare sector should not } \\
\text { be included in the Base case analysis; } \\
\text { If productivity losses, non-health care costs and/ } \\
\text { or unrelated healthcare costs are deemed important } \\
\text { for a specific treatment, they may be presented in a } \\
\text { separate analysis. }\end{array}$ \\
\hline France & $\begin{array}{l}\text { Choices In Methods for Economic } \\
\text { Evaluation }\end{array}$ & 2012 & Exclusion & $\begin{array}{l}\text { Future costs independent of the interventions being } \\
\text { studied are not considered }\end{array}$ \\
\hline Germany & Working Paper Cost Estimation & 2009 & $\begin{array}{l}\text { Exclusion in } \\
\text { base case; } \\
\text { Inclusion in } \\
\text { supplementary } \\
\text { analysis }\end{array}$ & $\begin{array}{l}\text { Summing up the controversial discussion on future costs, } \\
\text { the following recommendations apply: } \\
\text { Only future related costs should be considered in the } \\
\text { base case. } \\
\text { In sensitivity analyses, total healthcare costs (related } \\
\text { and unrelated healthcare costs) in life-years gained } \\
\text { should also be calculated if possible. }\end{array}$ \\
\hline
\end{tabular}


Table 2 Continued

\begin{tabular}{|c|c|c|c|c|}
\hline Country/area & Guidelines & Year & $\begin{array}{l}\text { Inclusion or } \\
\text { exclusion }\end{array}$ & Recommendations (if available) \\
\hline Ireland & $\begin{array}{l}\text { Guidelines for the Economic Evaluation } \\
\text { of Health Technologies in Ireland }\end{array}$ & 2019 & Not specified & $\begin{array}{l}\text { Only direct costs relevant to the public-funded health } \\
\text { and social care system should be included in the base } \\
\text { case. }\end{array}$ \\
\hline Nether- lands & $\begin{array}{l}\text { Guideline for Economic Evaluations in } \\
\text { Healthcare }\end{array}$ & 2016 & Inclusion & $\begin{array}{l}\text { If an intervention increases the life expectancy, } \\
\text { 'related' costs and 'non-related' costs should both } \\
\text { be considered in an economic evaluation of a life- } \\
\text { lengthening intervention. }\end{array}$ \\
\hline Norway & $\begin{array}{l}\text { Guidelines for the Submission of } \\
\text { Documentation for Single Technology } \\
\text { Assessment Of Pharmaceuticals }\end{array}$ & 2018 & Exclusion & $\begin{array}{l}\text { The health service costs related to future unrelated } \\
\text { illness will not be taken into consideration. }\end{array}$ \\
\hline Portugal & $\begin{array}{l}\text { Guidelines For Economic Drug Evaluation } \\
\text { Studies }\end{array}$ & 1998 & Not specified & $\begin{array}{l}\text { When the analysis adopts the perspective of society, } \\
\text { the costs included will be the direct costs of providing } \\
\text { healthcare, the costs of social services and other } \\
\text { sectors related to healthcare and the costs borne by } \\
\text { patients and their families. }\end{array}$ \\
\hline Slovak & $\begin{array}{l}\text { Guidelines for Economic Evaluation of } \\
\text { Healthcare Interventions }\end{array}$ & 2011 & Exclusion & $\begin{array}{l}\text { Direct healthcare costs should be included. These } \\
\text { encompass costs directly related to the treatment of } \\
\text { the disease as well as direct healthcare costs related } \\
\text { to the disease in life-years gained. }\end{array}$ \\
\hline Slovenia & $\begin{array}{l}\text { Rules on the Classification of Medicine } \\
\text { on the List }\end{array}$ & 2013 & Not specified & $\begin{array}{l}\text { The analysis should include direct health costs (total } \\
\text { direct costs of drug and total direct costs of other } \\
\text { healthcare procedures connected to changes in drug } \\
\text { therapy) for all future years. }\end{array}$ \\
\hline Sweden & $\begin{array}{l}\text { Assessment of Methods in Healthcare } \\
\text { and Social Services }\end{array}$ & 2018 & Not specified & $\begin{array}{l}\text { Which direct costs to include depends on the type of } \\
\text { method that is being evaluated. } \\
\text { In certain cases, costs for sectors of society other } \\
\text { than those delivering the services can be the most } \\
\text { important for the analysis. } \\
\text { The most important indirect cost is the reduced } \\
\text { productivity due to incapacity to work because of } \\
\text { disease or social problem. }\end{array}$ \\
\hline $\begin{array}{l}\text { Czech } \\
\text { Republic }\end{array}$ & Cost-effectiveness Guidelines & 2017 & Exclusion & $\begin{array}{l}\text { All relevant direct costs covered from health insurance } \\
\text { company perspective (medical and non-medical) to the } \\
\text { disease should be identified. }\end{array}$ \\
\hline $\begin{array}{l}\text { England \& } \\
\text { Wales }\end{array}$ & $\begin{array}{l}\text { Guide to the Methods of Technology } \\
\text { Appraisal } 2013\end{array}$ & 2013 & Exclusion & $\begin{array}{l}\text { Costs related to the condition of interest and incurred } \\
\text { in additional years of life gained as a result of treatmen } \\
\text { should be included in the reference-case analysis. } \\
\text { Costs considered to be unrelated to the condition or } \\
\text { technology of interest should be excluded. }\end{array}$ \\
\hline Finland & $\begin{array}{l}\text { Preparing a Health Economic Evaluation } \\
\text { to Be Attached to the Application for } \\
\text { Reimbursement Status and Wholesale } \\
\text { Price for A Medicinal Product }\end{array}$ & 2019 & Not specified & $\begin{array}{l}\text { The calculation of costs must include, irrespective of } \\
\text { the payer, all direct healthcare and comparable social } \\
\text { welfare costs related to the therapies that are being } \\
\text { compared. }\end{array}$ \\
\hline Poland & $\begin{array}{l}\text { Health Technology Assessment } \\
\text { Guidelines V.3.0 }\end{array}$ & 2016 & Not specified & $\begin{array}{l}\text { The suggested perspective only includes the } \\
\text { consideration of direct medical costs. }\end{array}$ \\
\hline Scotland & $\begin{array}{l}\text { Guidance to Submitting Companies for } \\
\text { Completion of New Product Assessment } \\
\text { Form }\end{array}$ & 2020 & Exclusion & $\begin{array}{l}\text { Costs should relate to resources that are under the } \\
\text { control of the NHS. } \\
\text { When sensitivity analyses include non-NHS/social } \\
\text { work costs, explicit methods of valuation are required. }\end{array}$ \\
\hline \multicolumn{5}{|l|}{ Oceania } \\
\hline New Zealand & $\begin{array}{l}\text { Prescription for Pharmacoeconomic } \\
\text { Analysis: Methods for Cost-Utility } \\
\text { Analysis V.2.2 }\end{array}$ & 2015 & Exclusion & $\begin{array}{l}\text { Indirect future healthcare costs including costs } \\
\text { associated with patients living longer and hence } \\
\text { consuming healthcare resources unrelated to their } \\
\text { initial diagnosis or treatment should not be included. }\end{array}$ \\
\hline Australia & $\begin{array}{l}\text { Guidelines for Preparing a Submission } \\
\text { to the Pharmaceutical Benefits Advisory } \\
\text { Committee }\end{array}$ & 2016 & Not specified & $\begin{array}{l}\text { Healthcare resource costs should be considered } \\
\text { including those incurred by the patient, and the public } \\
\text { or private healthcare provider }\end{array}$ \\
\hline
\end{tabular}

AMCP, Academy of Managed Care Pharmacy; ICER, Institute for Clinical and Economic Review; NHS, National Health Service; QALYs, qualityadjusted life-years. 
impact of including future unrelated medical costs in CEAs. If the HTA agency determines to include future unrelated medical costs, the ICERs may be significantly impacted, as indicated by previous research. ${ }^{15} 162032-35$ In this case, the ICER threshold recommended the current guidelines would be inappropriate and HTA agencies need to establish an explicit and systematic mechanism to adjust the ICER thresholds.

In addition to the research on future unrelated medical costs, it would be valuable to investigate how patient preference could be engaged ${ }^{36} 37$ and whether to consider future non-medical costs, ${ }^{18} 38$ as required by the societal perspective Future non-medical costs refer to the consumption during the life-years gained if the patient receives a life-extending intervention. There is no consensus on this issue. Nyman argued that future nonmedical costs should be excluded because the benefits of future non-medical consumption are not systematically included in the health outcomes. ${ }^{22}$ Other health economists disagree and persist that only inclusion of these costs could achieve utility maximisation. ${ }^{18} 3940$ Chinese health economists should pay attention to it to participate in the discussion on this topic.

\section{CONCLUSIONS}

The issue of future unrelated medical costs has been unresolved for over a decade. Recent progress in research leads to an increasing voice supporting the inclusion of these costs in CEA and prescription by some official pharmacoeconomic guidelines that an inclusion approach is recommended. Explicitly, the inclusion would increase the internal and external consistency of CEA and the comparability of results between different jurisdictions. Chinese HTA agencies and health economists should pay attention to this issue, and more research is warranted to inform the update of Chinese guidelines.

Contributors Conceptualisation and writing: SJ. Review: SJ and YW. Summary of guidelines: YW. Discussion and manuscript revision: SJ, YW, JZ, YJ, GG-EL and JW. All authors approved the submitted version. $\mathrm{SJ}$ is the guarantor responsible for the overall content.

Funding The authors have not declared a specific grant for this research from any funding agency in the public, commercial or not-for-profit sectors.

Competing interests None declared.

Patient consent for publication Not applicable.

Provenance and peer review Not commissioned; externally peer reviewed.

Data availability statement № data are available.

Supplemental material This content has been supplied by the author(s). It has not been vetted by BMJ Publishing Group Limited (BMJ) and may not have been peer-reviewed. Any opinions or recommendations discussed are solely those of the author(s) and are not endorsed by BMJ. BMJ disclaims all liability and responsibility arising from any reliance placed on the content. Where the content includes any translated material, BMJ does not warrant the accuracy and reliability of the translations (including but not limited to local regulations, clinical guidelines, terminology, drug names and drug dosages), and is not responsible for any error and/or omissions arising from translation and adaptation or otherwise.

Open access This is an open access article distributed in accordance with the Creative Commons Attribution Non Commercial (CC BY-NC 4.0) license, which permits others to distribute, remix, adapt, build upon this work non-commercially, and license their derivative works on different terms, provided the original work is properly cited, appropriate credit is given, any changes made indicated, and the use is non-commercial. See: http://creativecommons.org/licenses/by-nc/4.0/.

\section{ORCID iDs}

Shan Jiang http://orcid.org/0000-0003-1015-1278

Yawen Jiang http://orcid.org/0000-0002-0498-0662

\section{REFERENCES}

1 Drummond MF, Sculpher MJ, Claxton K. Methods for the economic evaluation of health care programmes. Oxford university press, 2015

2 Guoen L. Guidelines for the evaluation of Chinese pharmacoeconomics 2019, 2019.

3 Chen Z, Zhou L, Jiang S, et al. Identifying options of best value: use of economic evaluation in public health. China CDC Wkly 2020;2:75-8.

4 Jiang S, Chen Z, Wu J, et al. Addressing methodological and ethical issues in practicing health economic evaluation in China. J Glob Health 2020;10:020322.

5 de Vries LM, van Baal PHM, Brouwer WBF. Future costs in costeffectiveness analyses: past, present, future. Pharmacoeconomics 2019;37:119-30.

6 Rappange DR, van Baal PHM, van Exel NJA, et al. Unrelated medical costs in life-years gained. Pharmacoeconomics 2008;26:815-30.

7 van Lier LI, Bosmans JE, van Hout HPJ, et al. Consensusbased cross-European recommendations for the identification, measurement and valuation of costs in health economic evaluations: a European Delphi study. Eur J Health Econ 2018;19:993-1008.

8 Nederland Z. Guideline for economic evaluations in healthcare. Diemen: ZIN, 2016.

9 Garber AM, Phelps CE. Economic foundations of cost-effectiveness analysis. J Health Econ 1997;16:1-31.

10 Garber AM, Phelps CE. Future costs and the future of costeffectiveness analysis. J Health Econ 2008;27:819-21.

11 Lee RH. Future costs in cost effectiveness analysis. J Health Econ 2008;27:809-18

12 Meltzer D. Response to "Future costs and the future of costeffectiveness analysis". J Health Econ 2008;27:822-5.

13 Weinstein MC, Siegel JE, Gold MR, et al. Recommendations of the panel on cost-effectiveness in health and medicine. JAMA 1996;276:1253-8.

14 Kellerborg K, Perry-Duxbury M, de Vries L, et al. Practical guidance for including future costs in economic evaluations in the Netherlands: introducing and applying paid 3.0. Value Health 2020;23:1453-61.

15 van Baal P, Meltzer D, Brouwer W. Future costs, fixed healthcare budgets, and the decision rules of cost-effectiveness analysis. Health Econ 2016;25:237-48

16 Grima DT, Bernard LM, Dunn ES, et al. Cost-effectiveness analysis of therapies for chronic kidney disease patients on dialysis: a case for excluding dialysis costs. Pharmacoeconomics 2012;30:981-9.

17 van Baal $\mathrm{P}$, Morton A, Brouwer W, et al. Should cost effectiveness analyses for NICE always consider future unrelated medical costs? BMJ 2017;359:j5096.

18 Meltzer D. Accounting for future costs in medical cost-effectiveness analysis. J Health Econ 1997;16:33-64.

19 Perry-Duxbury M, Asaria M, Lomas J, et al. Cured today, ill tomorrow: a method for including future unrelated medical costs in economic evaluation in England and Wales. Value Health 2020;23:1027-33.

20 van Baal PHM, Feenstra TL, Hoogenveen RT, et al. Unrelated medical care in life years gained and the cost utility of primary prevention: in search of a 'perfect' cost-utility ratio. Health Econ 2007;16:421-33.

21 van Baal PHM, Wong A, Slobbe LCJ, et al. Standardizing the inclusion of indirect medical costs in economic evaluations. Pharmacoeconomics 2011;29:175-87.

22 Nyman JA. Should the consumption of survivors be included as a cost in cost-utility analysis? Health Econ 2004;13:417-27.

23 Borg S, Nahi H, Hansson M, et al. Cost effectiveness of pomalidomide in patients with relapsed and refractory multiple myeloma in Sweden. Acta Oncol 2016;55:554-60.

24 Excellence NIfH, Care. The guidelines manual, 2012

25 Kearns $B$. The relevance of future, unrelated health costs in economic evaluation in NICE appraisals. NICE dsu report 2020.

26 Chen Z, Jiang S, Wang Y. Pharmacoeconomics of obesity in China: a scoping review. Exp Rev Pharm Outcom Res 2021:1-9.

27 Jiang $Y$, Cai D, Chen D, et al. Economic evaluation of remdesivir for the treatment of severe COVID-19 patients in China under different scenarios. Br J Clin Pharmacol 2021;13. 
28 Jiang Y, Cai D, Chen D, et al. The cost-effectiveness of conducting three versus two reverse transcription-polymerase chain reaction tests for diagnosing and discharging people with COVID-19: evidence from the epidemic in Wuhan, China. BMJ Glob Health 2020;5:e002690.

29 Jiang Y, Jiang S, Ni W. Burden of cardiovascular diseases associated with fine particulate matter in Beijing, China: an economic modelling study. BMJ Glob Health 2020;5:e003160.

30 Gandjour A, Lauterbach KW. Does prevention save costs? Considering deferral of the expensive last year of life. J Health Econ 2005;24:715-24.

31 Morton A, Adler Al, Bell D, et al. Unrelated future costs and unrelated future benefits: reflections on NICE guide to the methods of technology appraisal. Health Econ 2016;25:933-8.

32 Kruse M, Sørensen J, Gyrd-Hansen D. Future costs in costeffectiveness analysis: an empirical assessment. Eur J Health Econ 2012;13:63-70.

33 Johannesson M, Meltzer D, O'Conor RM. Incorporating future costs in medical cost-effectiveness analysis. Med Decis Making 1997;17:382-9.

34 Manns B, Meltzer D, Taub K, et al. Illustrating the impact of including future costs in economic evaluations: an application to end-stage renal disease care. Health Econ 2003;12:949-58.

35 Meltzer D, Egleston B, Stoffel D, et al. Effect of future costs on costeffectiveness of medical interventions among young adults. Med Care 2000;38:679-85.

36 Jiang S, Anis AH, Cromwell I. Health-care practitioners' preferences for the return of secondary findings from next-generation sequencing: a discrete choice experiment. Genet Med 2020:1-9.

37 Jiang S, Gu Y, Yang F. Tertiary hospitals or community clinics? An enquiry into the factors affecting patients' choice for healthcare facilities in urban China. China Econ Rev 2020;101538.
38 Meltzer D. Future costs in medical cost-effectiveness analysis. In: Andrew J, ed. The Elgar companion to health economics, 2012.

39 Gandjour A. Consumption costs and earnings during added years of life - a reply to Nyman. Health Econ 2006;15:315-7.

40 Richardson JRJ, Olsen JA. In defence of societal sovereignty: a comment on Nyman 'the inclusion of survivor consumption in CUA'. Health Econ 2006;15:311-3.

41 Meltzer D, Johannesson M. Inconsistencies in the "societal perspective" on costs of the Panel on Cost-Effectiveness in Health and Medicine. Med Decis Making 1999;19:371-7.

42 Feenstra TL, van Baal PHM, Gandjour A, et al. Future costs in economic evaluation. A comment on Lee. $J$ Health Econ 2008;27:1645-9.

43 van Baal P, Meltzer D, Brouwer W. Pharmacoeconomic guidelines should prescribe inclusion of indirect medical costs! a response to Grima et al. Pharmacoeconomics 2013;31:369-73.

44 Gros B, Soto Álvarez J, Ángel Casado M. Incorporation of future costs in health economic analysis publications: current situation and recommendations for the future. Expert Rev Pharmacoecon Outcomes Res 2015;15:465-9.

$45 \mathrm{McCabe}$ C. Expanding the scope of costs and benefits for economic evaluations in health: some words of caution. Pharmacoeconomics 2019;37:457-60.

46 Tew M, Clarke P, Thursky K, et al. Incorporating future medical costs: impact on cost-effectiveness analysis in cancer patients. Pharmacoeconomics 2019;37:931-41.

47 van Baal P, Morton A, Meltzer D, et al. Future unrelated medical costs need to be considered in cost effectiveness analysis. Eur $J$ Health Econ 2019;20:1-5. 